\section{Photodefinable electro-optic polymer for high-speed modulators}

M. Balakrishnan, M. Faccini, M.B.J. Diemeer, W. Verboom, A. Driessen, D.N. Reinhoudt and A. Leinse

Direct waveguide definition of a negative photoresist (SU8) containing tricyanovinylidenediphenylaminobenzene (TCVDPA) as electro-optic (EO) chromophore, has been demonstrated for the first time. This was possible by utilising the chromophore low absorption window in the UV region allowing crosslinking of the host polymer by exposing to UV light followed by thermal curing. TCVDPA was modified by attachment of bulky side groups. This reduced the intermolecular interactions and resulted in an increased EO $\left(\mathrm{r}_{33}\right)$ coefficient.

Introduction: Over the past decade the demand for telecommunication services and bandwidth has boomed. To handle this ever-increasing demand, high-speed electro-optic (EO) modulators operating over $100 \mathrm{GHz}$ are required [1]. The currently used EO modulators based on $\mathrm{LiNbO}_{3}$ are limited in bandwidth to $40 \mathrm{GHz}$, because at higher frequencies the velocity mismatch between the optical wave and the electrical travelling wave yields too large dephasing and consequently too short interaction lengths. To handle such high modulation frequencies a better performing material is required. Second-order nonlinear optical (NLO) polymers [2,3] were proposed two decades ago as useful candidates for this application. Though NLO polymers have the potential for high nonlinearity, the nonlinearity of the individual chromophores does not translate completely onto a macroscopic scale. This is because electrostatic intermolecular interactions lead to antiparallel clustering of the chromophores during electric field induced poling. These intermolecular interactions can be reduced by modifying the shape of the chromophore (making it more spherical) and thereby preventing their closer approach [4]. For long-term applications the chromophores should have a high photochemical stability at the operating wavelength and a high stability of the poling order at the operating temperature. TCVDPA has the highest reported photochemical stability [5]. In addition, its NLO figure of merit is higher than dimethylaminonitrostilbene (DANS) and disperse red (DR1). The difference between the glass transition temperature $\left(T_{g}\right)$ of the polymer and the operating temperature, which determines the stability of the poling order, requires polymers with a high $T_{g}$ of about $200^{\circ} \mathrm{C}$. When the NLO chromophores are incorporated in a photodefinable polymer electro-optically active waveguides can be obtained by direct photodefinition. Compared with the reactive ion etching technique, this requires fewer processing steps and yields less sidewall roughness. In this Letter we report for the first time the direct photodefinition of an electro-optic polymer, i.e. TCVDPA in the SU8 host. Improvement of the poling efficiency by modifying TCVDPA with bulky side groups is also presented.
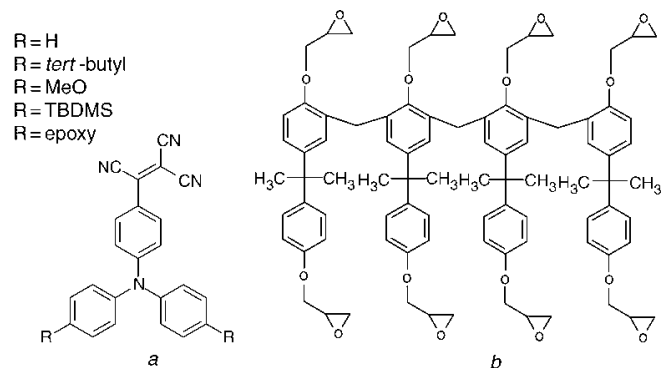

Fig. 1 TCVDPA and its modifications; SU8

$a$ TCVDPA and its modifications $b$ SU8

Materials: The TCVDPA chromophore (Fig. $1 a, \mathrm{R}=\mathrm{H}$ ) was used in the current work. It consists of a single benzene electron bridge between a tricyanovinyl acceptor and a diarylamino donor. For photodefinition, TCVDPA is incorporated as a guest in the SU8 (Fig. 1b) host. TCVDPA with different bulky groups $(\mathrm{R}=$ tert-butyl, methoxy (MeO) and tert-butyl-dimethylsilane (TBDMS)) were prepared to study the inhibition of the intermolecular interactions. The $T_{g}$ of uncrosslinked SU8 is $60^{\circ} \mathrm{C}$. By crosslinking, the $T_{g}$ can be raised to about $200^{\circ} \mathrm{C}$.
Photodefinition: Photodefinition of the SU8-TCVDPA guest-host (GH) polymer is demonstrated by exploiting the low UV absorption window of the TCVDPA chromophore shown in Fig. 2, in which region most of the other NLO chromophores are highly absorbing. The photodefinition process is shown in Fig. 3. SU8 $5 \mathrm{wt} \%$ TCVDPA was spun on a Si substrate at $3000 \mathrm{rpm}$ to give a film thickness of $2 \mu \mathrm{m}$. It was then baked at $95^{\circ} \mathrm{C}$ for $5 \mathrm{~min}$ on a hotplate (soft bake). Subsequently, the polymer film was exposed to UV light with a $\mathrm{Cr}$ contact mask for 5 min in a Karl Süss mask aligner MA55 $(365,405$ and $435 \mathrm{~nm}$ ) and cured at $95^{\circ} \mathrm{C}$ for $5 \mathrm{~min}$ (post-bake). The unexposed regions are uncrosslinked and are removed by development.

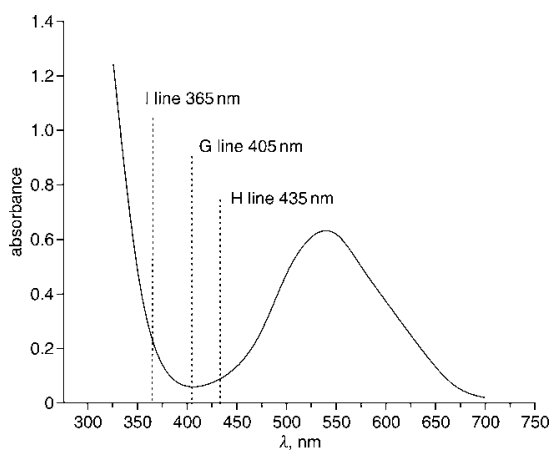

Fig. 2 Absorption spectrum of TCVDPA

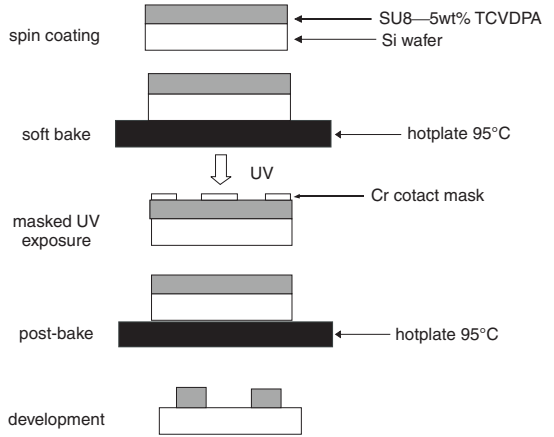

Fig. 3 Photodefinition process

Poling: The polymer should be noncentrosymmetric in order to exhibit second-order nonlinearity. This is achieved by poling whereby the polymer is heated to its glass transition temperature $\left(T_{g}\right)$ and the chromophores are aligned by applying an electric field typically of the order of $100 \mathrm{~V} / \mu \mathrm{m}$. Poling was carried out in a crosslinked polymer film and not in a photodefined waveguide in order to have a large poled region for measurement of the $\mathrm{r}_{33}$. A $2 \mu \mathrm{m}$-thick SU8 film with $25 \mathrm{wt} \%$ TCVDPA was spun on a glass wafer coated with an indium tin oxide (ITO) layer which serves as the bottom electrode for poling. The film was then heated on a hotplate at $95^{\circ} \mathrm{C}$ for $1 \mathrm{~h}$ and in the oven at $95^{\circ} \mathrm{C}$ for $8 \mathrm{~h}$ under vacuum to remove the solvent. The film was exposed to UV light in a Karl Süss mask aligner MA55 for 2 min and cured at $95^{\circ} \mathrm{C}$ for $15 \mathrm{~min}$. A $100 \mathrm{~nm}$ gold layer was sputtered on the polymer as the top electrode for poling. It was observed that when equipped with TCVDPA as guest, the $\left(T_{g}\right)$ of the crosslinked SU8 is reduced considerably owing to the plasticising effect of the chromophores. The $T_{g}$ of the cured sample was around $45^{\circ} \mathrm{C}$. Therefore the sample was poled by heating it to $45^{\circ} \mathrm{C}$ and applying an electric field of $100 \mathrm{~V} / \mu \mathrm{m}$. Poling was carried out for about $40 \mathrm{~min}$. The sample was cooled to room temperature and the electric field removed. An $r_{33}$ coefficient of $6 \mathrm{pm} / \mathrm{V}$ was measured at $830 \mathrm{~nm}$ immediately after poling by the Teng-Man reflection technique [6]. To make a comparative study, the $\mathrm{r}_{33}$ coefficient was also measured in a high $T_{g}$ polymer, polysulfone (PS host) at different wt $\%$ of TCVDPA (guest). All the $r_{33}$ values were measured at $830 \mathrm{~nm}$. This was poled at its $T_{g}$ under similar poling conditions as SU8 $-25 \mathrm{wt} \%$ TCVDPA. The $T_{g}$ of polysulfone against the $w t \%$ of TCVDPA is shown in Fig. 4, which also shows the $r_{33}$ of the PS-TCVDPA measured at different concentrations of TCVDPA. A deviation from the linear behaviour was observed above $15 \mathrm{wt} \%$ of TCVDPA. The measured $\mathrm{r}_{33}$ was $9 \mathrm{pm} / \mathrm{V}$ at $25 \mathrm{wt} \%$ TCVDPA. The difference in $r_{33}$ coefficients between SU8-25 wt \% TCVDPA 
$(6 \mathrm{pm} / \mathrm{V})$ and PS- $25 \mathrm{wt} \%$ TCVDPA $(9 \mathrm{pm} / \mathrm{V})$ can be attributed to the fact that the $T_{g}$ of the cured SU8 - $25 \mathrm{wt} \%$ TCVDPA is so close to room temperature (about $45^{\circ} \mathrm{C}$ ) that the poling order relaxes rapidly when the poling field is removed at room temperature. This is can be prevented by equipping TCVDPA with epoxy groups (Fig. $1 a, \mathrm{R}=$ epoxy) and crosslinking TCVDPA-epoxy with SU8.

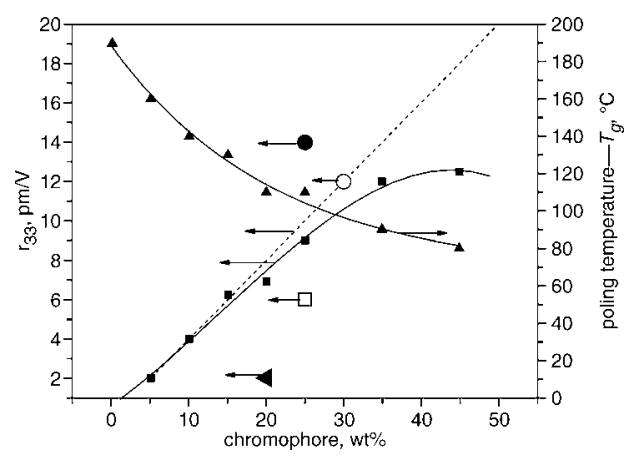

Fig. 4 Measured $r_{33}$ coefficients for different TCVDPA modifications in SU8 and PS at $830 \mathrm{~nm}$

- $\mathrm{r}_{33}$ PS - TCVDPA

A $T_{g}$ PS - TCVDPA

- - - $r_{33}$ PS - TCVDPA linear fit

$r_{33}$ SU8 - TCVDPA

- $\mathrm{r}_{33}$ PS - TCVDPA-tert-butyl

O $\mathrm{r}_{33}$ PS - TCVDPA-MeO

$4 \mathrm{r}_{33}$ PS - TCVDPA-TBDMS

The poling behaviour of TCVDPA-tert-butyl, TCVDPA-MeO, and TCVDPA-TBDMS was studied by incorporating them as guests in PS at concentrations at which the $r_{33}$ of PS-TCVDPA deviates from linear behaviour. The measured $r_{33}$ values are shown in Fig. 4. At $25 \mathrm{wt} \%$, TCVDPA tert-butyl shows an enhancement in $\mathrm{r}_{33}$ of $5 \mathrm{pm} / \mathrm{V}$, and at $30 \mathrm{wt} \%$ TCVDPA-MeO shows an enhancement of $2 \mathrm{pm} / \mathrm{V}$ compared with TCVDPA. These data clearly demonstrate the effect of the bulky groups. In the case of TCVDPA-tert-butyl the enhancement in $r_{33}$ is even higher than that predicted by the linear fit. This indicates that some intermolecular interactions are already present even at low TCVDPA concentration $(<15 \mathrm{wt} \%)$ in PS. Contrary to our expectations, at $20 \mathrm{wt} \%$ TCVDPA-TBDMS gave an $\mathrm{r}_{33}$ of only $2 \mathrm{pm} / \mathrm{V}$ compared with $7 \mathrm{pm} / \mathrm{V}$ measured with TCVDPA. This can be explained by the high molecular weight of TCVDPA-TBDMS which not only reduces the chromophore number density for a given $w t \%$ but also reduces the poling efficiency owing to the restricted motion of the chromophores. using the low UV absorption window of TCVDPA chromophore. The crosslinked polymer system was poled and an $\mathrm{r}_{33}$ of $6 \mathrm{pm} / \mathrm{V}$ at $830 \mathrm{~nm}$ was measured. Increasing the $r_{33}$ by the attachment of bulky groups to the chromophore to inhibit intermolecular interactions was demonstrated.

Acknowledgments: This research work is supported by the Dutch Technology Foundation STW, Applied Science Division of NWO and the Technology Program of the Ministry of Economic Affairs and carried out within the framework of the project TOE 6067 'Broadband and wavelength selective modulators for optical communication based on electro-optic polymers'.

(C) IEE 2006

Electronics Letters online no: 20063535 doi: 10.1049/el:20063535

M. Balakrishnan, M.B.J. Diemeer and A. Driessen (Integrated Optical Microsystems, University of Twente, MESA+ Institute for Nanotechnology, P.O. Box 217, 7500 AE Enschede, The Netherlands)

E-mail: m.balakrishnan@ewi.utwente.nl

M. Faccini, W. Verboom and D.N. Reinhoudt (Laboratory of Supramolecular Chemistry and Technology, University of Twente, MESA+ Institute for Nanotechnology, P.O. Box 217, 7500 AE Enschede, The Netherlands)

A. Leinse (LioniX BV, P.O. Box 456, Enschede 7500 AH, The Netherlands)

\section{References}

1 Shi, Y., et al.: 'Low half voltage polymeric electro-optic modulator achieved by controlling chromophore shape', Science, 2000, 288, pp. $119-122$

2 Meredith, G.R., Van Dusen, J.G., and Williams, D.J.: 'Optical and nonlinear optical characterization of molecularly doped thermotropic liquid crystalline polymers', Macromol., 1998, 15, pp. 1385-1389

3 Cheng, D., et al.: 'Demonstration of $110 \mathrm{GHz}$ electro-optic polymer modulators', Appl. Phys. Lett., 1997, 70, pp. 3335-3337

4 Robinson, B.H., and Dalton, L.R.: 'Monte Carlo statistical mechanical simulations of the competition of intermolecular electrostatic and poling field interactions', J. Phys. Chem. A, 2000, 104, pp. 4785-4795

5 Gonzales, A.G., et al.: 'Photostability of electro-optic polymers possessing chromophores with efficient amino donors and cyano containing acceptors', J. Opt. Soc. Am. B, 2001, 18, pp. 1846-1853

6 Teng, C.C., and Man, H.T.: 'Simple reflection technique for the measuring the electro-optic coefficient of poled polymers', Appl. Phys. Lett., 1990, 56, pp. 1734-1736 
Copyright of Electronics Letters is the property of IEE and its content may not be copied or emailed to multiple sites or posted to a listserv without the copyright holder's express written permission. However, users may print, download, or email articles for individual use. 